\title{
LA INICIACIÓN RITUAL DE LA PARTERA EN LAS ETNOGRAFIAS MAYAS
}

Martha Ilia NAJERA C, Centro de Estudios Mayas

El papel de la partera en las diversas comunidades mayenses alcanza gran relevancia, pues representa la seguridad y el confort que requiere una joven embarazada; no obstante, se ha modificado a través de la historia. El cargo, en términos generales, es ocupado por mujeres, sin embargo, por ejemplo entre los tojolabales, ${ }^{1}$ los chontales ${ }^{2}$ y los ch'oles también se incluyen hombres. El conocimiento que posee significa poder y aquel que tiene un mayor saber es un ser más completo, alcanza una cierta autoridad dentro de su comunidad y eleva su estatus social.

En la época prehispánica las parteras, a quienes fray Diego de Landa llamaba hechiceras, tenían una fiesta especial llamada Ixcil Ixchel, 'el baño de Ixchel', dentro del haab. Ésta se llevaba a cabo en el mes Zip con la participación conjunta de los médicos. Como el nombre de la ceremonia lo dice, se honraba a Ixchel, diosa "de la medicina y de hacer criaturas"; también se veneraba a otras deidades de la medicina: Itzamná, Cib Bolon Tun y Ahau Chamahes. Durante la fiesta consagraban los bultos donde guardaban sus objetos sagrados, "sacaban los envoltorios de sus medicinas en que traían muchas niñerías y sendos idolillos de la diosa de la medicina que llamaban Ixchel..." y unas piedras de la suerte llamadas am (Landa, 1966: 93), lo cual nos indica que entre sus funciones estaba la adivinación, que las parteras realizaban durante el embarazo y parto.

Los breves comentarios de Landa sobre las parteras permiten deducir que llevaban a cabo sus propias ceremonias; por lo tanto, constituían

${ }^{1}$ Gudrun Lenkersdorf, comunicación personal.

${ }^{2}$ El diccionario chontal de Turner (1971: 290) reporta la voz masculina para este oficio: partero(a) linnomof'i yale. 
un grupo especializado, que seguramente exigiría un ritual de iniciación para integrar miembros nuevos.

En algunas comunidades mayas contemporáneas aún se conservan los rituales iniciáticos que precisa una partera para tener acceso al oficio; sin embargo, coexisten dos clases de parteras: las que requieren una iniciación y las comadronas experimentadas que ejercen su oficio sin una validación sobrenatural. Las que dicen alcanzar esa validación logran una mayor relevancia, ya que la sanción divina le otorga validez al ritual, lo legitima y demuestra que la partera no actúa a título personal, sino que es depositaria de un mandato divino, lo que le da el reconocimiento de su comunidad.

En este artículo, basado en la metodología de la historia comparada de las religiones, se analizan primordialmente los símbolos religiosos asociados al ritual iniciático al que las parteras se someten, tomando en cuenta que en ciertos casos, dado que el ritual otorga legitimidad ante su comunidad, algunas conductas arquetípicas de las iniciaciones, se justifican precisamente para ganar el respeto del grupo social. De acuerdo con las referencias etnográficas encontradas, principalmente se analizan los rituales de los grupos zutuhil, quiché y mochó, y se hacen breves referencias a los ixiles, sin desconocer que en otras comunidades pueden existir estos rituales, pero no se han reportado.

De acuerdo con el testimonio de diferentes parteras iniciadas, éstas reciben su conocimientos por una doble vía: $a$ ) el rito por el cual se les otorga un poder místico y una sanción divina que les proporciona afinidad con las materias médicas y las capacita para activar las virtudes de las hierbas, y $b$ ) la experiencia adquirida al acompañar en su oficio a un pariente mayor, ya sea la madre, la abuela o la suegra, para quienes primero trabajan como asistentes, pues el cargo, en la mayoría de los casos, es hereditario (Bunzel, Cichicastenango: 119$){ }^{3}$ Por el rito, señalan los informantes, la mujer recibe conocimientos sobrenaturales, los espíritus de las parteras ya fallecidas le comunican durante sus experiencias oníricas, entre otras cosas: cómo despertar las virtudes contenidas en las plantas; cómo predecir el destino del recién nacido empleando diversos signos; el número de hijos que la madre podrá concebir, o a quién dirigir sus oraciones. Gracias a la observación y a su trabajo como ayudantes aprenden a conocer y a seleccionar las hierbas u otros medicamentos, a dar masajes, en caso necesario a colocar correctamen-

${ }^{3}$ El libro de Bunzel, según la autora: "constituye un estudio exploratorio de la villa de Chichicastenango en el departamento de Quiché, ubicada en el altiplano occidental de Guatemala. El trabajo de campo se realizó en los años de 1930-1933." 
te al feto manipulando el vientre de la madre, a saber el momento del nacimiento, las posiciones de parto que la madre puede adoptar, etcétera.

La labor que desempeñan estas mujeres iniciadas dentro de su comunidad es de verdaderas especialistas no sólo en obstetricia, sino también en el campo de lo sagrado. El cargo en general recae en personas de edad madura, casadas y con hijos. Entre los quichés uno de los requisitos es no ser vírgenes, dado que carecerían de experiencia; se prefiere que estén alejadas de la edad reproductiva, pues el "calor" que emana la parturienta puede ser dañino para las que todavía desean concebir; sin embargo, una razón práctica es que sus hijos son ya mayores y ellas pueden dedicarle más tiempo a su trabajo.

Podríamos dividir para su estudio el ritual iniciático de la partera en tres etapas, de acuerdo con la clasificación sugerida por Arnold van Gennep (1986): ${ }^{4}$ la primera es la de separación; la mujer sufre una muerte simbólica; con ello se aparta de su antigua situación dentro de la estructura social y de las demás mujeres de su comunidad. $\mathrm{Al}$ recuperarse y renacer ritualmente, penetra en la siguiente etapa, la de transición; en ésta se convierte en un ser ambiguo, aún no tiene atributos ni rango, ya no está clasificada dentro de su antigua situación social, y todavía no es un ser consagrado; es un periodo "liminar", de margen, durante el cual experimenta diversos viajes extáticos, así como el encuentro con objetos insólitos.

Para alcanzar la tercera etapa o de "incorporación", la mujer tiene que ser reconocida por un iniciado; entre ixiles el iniciado puede ser otra partera, ${ }^{5} \mathrm{y}$ entre los quichés la autoridad religiosa de la comunidad, el chamán; los iniciados realizan una última ceremonia para confirmarla en su nuevo estado; con ello adquiere nuevos atributos, derechos y obligaciones. Es una especialista de lo sagrado que tiene en sus manos el difícil arte de auxiliar a la madre, por un lado, y, por otro, de introducir al recién nacido en este mundo profano, ayudarlo en el desarrollo de su personalidad, interpretando los mensajes enviados por los seres sobrenaturales.

El primer requisito para la iniciación es nacer con un designio divino, que se manifiesta, de acuerdo con los quichés, porque el día de su nacimiento fue una fecha especial dentro del calendario ritual, que lo hace participar de la esencia del dios que rige ese periodo, o bien venir

${ }^{4}$ La primera versión en francés del libro de Gennep, clásico de la antropología de la religión, data de 1909.

${ }^{5}$ Mario H. Ruz, comunicación personal. 
al mundo con una parte del saco amniótico adherido al cuerpo (Cosminsky, 1977: 308). ${ }^{6}$

Otros, como los mochó, creen que ese "don destino" o "don herencia" se adquiere desde el momento de la concepción. Es la misma marca, señalan García Ruiz y Petrich, que reciben ciertos hombres extraordinarios como el qaman o chamán, el defensor del individuo contra el mal (García y Petrich, 1983: 45). ${ }^{7}$

En términos generales, la predestinación se manifiesta en la edad adulta y a veces, como entre los mochós, en la adolescencia. La mujer lo sabe porque recibe "su aire o el soplo de fuego" (García y Petrich, 1983: 47); es decir, una manera de manifestarse de los seres incorpóreos, una ráfaga, o bien algo que quema. Gracias a esta validación sobrenatural, las mujeres están capacitadas para acercarse a lo sagrado, interpretar sueños y fungir como intermediarias entre el mundo de los hombres y de los seres invisibles.

Algunas mujeres predestinadas, reportan Paul y Paul (1975: 710711) para los zutuhiles, ${ }^{8}$ son las que sufren una grave y larga dolencia, a veces con constantes recaídas; durante su enfermedad caen en la seudoconciencia, se aíslan, se retiran de la comunidad de los vivientes, lo que equivale simbólicamente a una muerte iniciática y al primer periodo de su iniciación. Su muerte simboliza una regresión al estado embrionario, el retorno a los orígenes cósmicos, lo que renueva su energía y las faculta para un renacimiento con cualidades espirituales superiores. Su recuperación también forma parte del ritual; muerto para la vida profana, renace en una vida sagrada (Eliade, 1975: 68-69; 1982: 45). Durante su enfermedad la futura partera se aísla de su grupo social, es un ser frágil y expuesto al designio de los seres sobrenaturales. El sufrimiento corporal en las iniciaciones está destinado a producir personas fuera de lo común, distinguidas, y por éste los iniciados se adhieren con más firmeza a su vocación.

$\mathrm{La}$ angustia de esta falta de salud insta a la mujer a una consulta con el especialista en lo sagrado, quien le señala que la causa de su mal es haber desobedecido el designio divino, la previene de que empeorará si

${ }^{6} \mathrm{El}$ trabajo de campo de esta autora se llevó a cabo en las aldeas de Cuchexic y Novillero en el pueblo de Santa Lucía Utatlán, en 1967-1968 y enero y agosto de 1974.

${ }^{7}$ Las investigaciones entre los mochó las realizaron los investigadores a principio de la década de los ochentas.

${ }^{8}$ El trabajo de campo se llevó a cabo en San Pedro la Laguna y Santiago Atitlán con hablantes zutuhiles durante 1941 y en una serie de visitas posteriores que se extendieron hasta 1974. En Santiago Atitlán los autores mencionan que los patrones de reclutamiento de las parteras se presentan en forma atenuada. 
no realiza el oficio para el que está predestinada. Las mujeres muestran gran resistencia a dedicarse a esta profesión, pues sus maridos generalmente se oponen porque descuidan el hogar, y en muchos casos la remuneración económica no es muy alta.

Durante el periodo "liminar", la mujer realiza viajes extáticos a través de diversas imágenes oníricas arquetípicas; su alma visita lugares misteriosos, vuela y asciende al cielo, o bien a las regiones del inframundo, sitios en los que tiene contacto con los seres sobrenaturales, quienes comunican su voluntad a la iniciada. Dado que su alma abandona el cuerpo, esto equivale también a una muerte provisional; al despertar es un ser que ha vivenciado una renovación espiritual. Así, la iniciada muere y renace un sinnúmero de veces.

En algunos de los sueños narrados por las informantes zutuhiles y quichés, los seres sobrenaturales con los que tiene contacto son los espíritus de las parteras fallecidas, quienes reprenden a las mujeres y las amenazan con provocar la muerte si no cumplen su mandato (Paul y Paul, 1975: 710-711; Cominsky, 1977: 300). Los mismos espíritus son los que en otros sueños instruyen a la mujer sobre la manera de desempeñar su oficio y resolver partos difíciles.

La partera zutuhil agrega que aquellos espíritus de las parteras le aseguraron que la instruirían en su papel de comadrona y la asistirían en partos difíciles (Paul y Paul, 1975: 710-711); al ponerse en contacto con lo sagrado, aprende el oficio para el que está destinada. Los espíritus de las parteras toman "posesión" de la mujer y proceden a guiarla, lo que es un requisito más para ser iniciada; por ello, en teoría no puede negarse, toda resistencia sería inútil (Eliade, 1975: 8), su destino está escrito por ser una decisión divina.

En las imágenes oníricas también están presentes las cavernas dentro de las montañas sagradas, propias de las iniciaciones chamánicas. La cueva es el lugar donde los chamanes tienen acceso al conocimiento, pues entran en contacto con los espíritus de sus antecesores y con las deidades protectoras. Cuenta una partera zutuhil cómo, cuando caminaba por un pueblo vecino, se encontró dentro de una colina, en una cámara con una gran alfombra. Sobre un estrado había varias parteras completamente blancas que ya habían fallecido. ${ }^{9}$ Las mujeres de blanco le recomendaron aceptar de sus pacientes cualquier obsequio por pequeño que fuera; de lo contrario sufriría por toda la eternidad, y para demostrar-

${ }^{9} \mathrm{El}$ blanco, en este contexto puede vincularse con el simbolismo lunar, o bien, según reportan en Jacaltenango, designa a alguien que tiene poder mágico; a esas personas se les denomina $t s a c-a n-s-k u l$, 'su corazón es blanco'. 
lo la condujeron a otra cámara subterránea, donde tres parteras se quemaban por haber despreciado los regalos de sus pacientes (Paul y Paul, 1975: 711).

Las parteras fallecidas actúan como espíritus tutelares y maestras de iniciación; la mujer, como un novicio que, al viajar al inframundo, recibe la revelación de lo sagrado. Su viaje a la caverna simboliza también un regreso al útero materno, el retorno a la Gran Madre ctónica, el descenso al inframundo, parte primordial del rito iniciático necesario para renacer como un ser superior, después de trascender la muerte. En el más allá también reside la sabiduría, ahí se reúnen los antepasados con sus conocimientos y la partera, al entrar en contacto con ellos asimila ese saber.

Los sueños son en especial significativos para los indígenas; los consideran experiencias que ocurren en realidad, o bien revelaciones de sucesos futuros. Algunos, como los de las iniciaciones de los hombres sagrados, son estereotipos culturales y contienen siempre los mismos elementos: los espíritus se presentan dentro de una gran sala para instruir y ordenar sus destinos (Garza, 1990: 48-49, 206).

$\mathrm{Al}$ igual que en las iniciaciones chamánicas, la partera comparte otras experiencias rituales: el encuentro con objetos "insólitos" que por ello poseen un poder mágico o sagrado; son los llamados "cuentecitos" (¿cuentecitas) por los zutuhiles de Santiago Atitlán (Paul y Paul, 1975: 717). Se cree que son mensajes enviados por los seres sobrenaturales; algunos pueden ser instrumentos propios de su trabajo, como las tijeras empleadas para el corte del cordón umbilical, o bien ciertos objetos con un profundo contenido simbólico.

Entre éstos podríamos mencionar el localizado por una mujer zutuhil: una concha, que en principio se negó a recoger tal vez por temor a su fuerza sagrada, o bien porque el hacerlo implicaría la aceptación de sus funciones; en su siguiente sueño se le presentaron una vez más los espíritus de las parteras, la reprendieron por su rechazo y le ordenaron que la guardara dentro de un pañuelo, conformando un envoltorio.

Este bulto nos recuerda el varapunta, donde los chamanes quichés depositan sus objetos sagrados empleados para la adivinación, cuyas raíces datan de la Mesoamérica prehispánica. Fray Diego de Landa (1966: 93) señala que aquellos cuyas actividades se vinculaban con la medicina, entre los que se contaban las parteras, guardaban la parafernalia sagrada en ciertos bultos que contenían, entre otros objetos, la imagen de Ixchel, deidad protectora de los partos y vinculada también con la medicina, la Luna y el tejido; además los bultos contenían unas pequeñas cuentas llamadas am que les servían para realizar sus pro- 
nósticos, parte importante de las funciones de las parteras. Estos atados, según las creencias prehispánicas, tenían una función trascendental, dado que los dioses los empleaban para ordenabar, dirigir, aconsejar, auxiliar y hablar a su gente (Garduño, s. f.).

La concha que encontró aquella mujer zutuhil, y con la cual configuró parte de su envoltorio sagrado, es un elemento con un profundo simbolismo religioso. Las parteras pueden emplearlas en sus curaciones y se cree que poseen poderes milagrosos; al evocar las aguas de donde surgen, participan del simbolismo de la fecundidad, estrechamente relacionado con lo acuático; y puesto que su forma recuerda el órgano sexual femenino, se asocian a la matriz y al nacimiento, al mundo subterráneo donde la vida, cual semilla, tiene su origen (Chevalier y Gheerbrant, 1988: 332-333). Para enriquecer el significado de la concha recuérdese aquel rito prehispánico entre los mayas yucatecos que describe Landa (1966: 44-47), donde las niñas, cuando se sometían al ritual de iniciación en la pubertad, llevaban sobre el pubis una concha atada a la cintura, vinculada con su virginidad; al quitárselas, se les facultaba para contraer matrimonio en el momento en que sus padres lo decidieran. Tal vez por ello es que los zutuhiles consideran que cuando una mujer sufre esterilidad, la concha se debe restregar sobre el vientre, y si al hacerlo produce un sonido "como un bebé que llora"; esto es señal de esperanza (Paul y Paul, 1975: 712).

Los objetos sagrados tienen la facultad de desaparecer y reaparecer por voluntad propia y su destino está ligado a quienes los poseen; esto sugiere una entidad anímica, por lo que la partera debe cuidarlos con esmero, pues si los pierde o se destruyen, la partera puede fallecer. Entre los objetos mágicos y la partera, pues, existe una comunicación anímica, que si bien la refuerza y acompaña en el desempeño de su labor, puede recibir un castigo divino si los descuida.

Otra informante zutuhil reveló su encuentro con una navaja que tenía grabados en el mango un pez y un niño, lo que el chamán interpretó como un instrumento necesario para que la partera cortara el cordón umbilical (Paul y Paul, 1975: 710-711). No creo que los elementos asociados a la navaja sean fortuitos; por ejemplo, la imagen del niño alude a su futura profesión; el pez, por alegoría del elemento donde vive, el agua, se asocia al nacimiento y a la renovación cíclica; es también símbolo de vida y fecundidad en razón de su prodigiosa capacidad de reproducción y del abundante número de descendientes. Al estar escondido en las profundidades, participa también de la fuerza sagrada del abismo, del inframundo y por ende de la sabiduría (Chevalier y Gheerbrant, 1988: 824). 
Cierta partera quiché de Santa Lucía Utatlán encontró, cuando era joven, un espejo con mango blanco y rojo; en él se reflejaba la cara de una mujer con una larga cabellera blanca, la interpretó como la imagen de santa Ana, la patrona de las parteras, y la parte roja del mango fue tomada como el fuego del baño de vapor (Cosminsky, 1976: 107, 308).

Podemos agregar que el rojo es además símbolo de la sangre que se derrama durante el parto, pero también es la condición de la vida, de la energía que corre por el cuerpo. El blanco, que se opone al rojo, puede asociarse con el simbolismo lunar y con el espíritu de las parteras fallecidas, con la iniciación de la partera y su iluminación; además de vincularse con el semen engendrador y sustentador del nuevo ser dentro del vientre materno. Es un color neutro, pasivo, recuerda la blancura virginal propia de los recién nacidos.

Por otro lado, el espejo, en tanto superficie reflectante, encierra un rico simbolismo en el terreno del conocimiento, que se vincula con la revelación de la verdad; por ello se considera adivinatorio, al igual que los cristales de roca que emplean los chamanes en sus adivinaciones, dentro de los cuales ven la etiología de la enfermedad. El saber de los seres sobrenaturales se refleja en el espejo; de aquí que sea un atributo propio para la partera, entre cuyas funciones está la de conocer los designios divinos; es también la entrada a otras realidades, al mundo sagrado, en el cual la partera necesita incursionar. Asimismo, el espejo la protege de las influencias maléficas; $y$ al revelar su verdadera naturaleza, las aleja (Chevalier y Gheerbrant, 1988: 189-193, 474-476). ${ }^{10}$ Por lo tanto, es un objeto que por sus múltiples simbolismos se identifica con la profesión de la partera. De todo esto precisa la comadrona al recibir al niño, que es un ser débil expuesto a cualquier daño.

El encuentro con objetos ricos en contenido simbólico se equipara a recibir mensajes enviados por los seres sobrenaturales, simboliza la sanción divina de su oficio, y valida la posición de la partera como un ritual de especialistas (Cosminsky, 1976: 107).

A pesar de todo el proceso de iniciación vivido (el "don-destino", los presagios —enfermedades, sueños, encuentro con objetos insólitos-), todavía se consulta a un chamán para que interprete las señales y las verifique. El especialista, con sus conocimientos del mundo sagrado, comprueba si la aspirante nació con un pedazo del saco

${ }^{10}$ De allí que los tzotziles los cuelguen en el pecho de las imágenes de sus santos, para "reflejar" y proyectar el daño sobre quien lo envía. Mario H. Ruz, comunicación personal. 
amniótico adherido al cuerpo, hecho fácil de corroborar pues las madres de las predestinadas suelen guardar la membrana seca.

Cuando el chamán considera que la mujer ha cumplido los requisitos necesarios para ser iniciada, pasa a la tercera etapa del ritual, la de "incorporación" de la partera a su naciente vida. El chamán zutuhil enciende velas durante el día en la iglesia frente a la imagen de santa Ana y por la noche ante la cruz de la montaña para hacer la "costumbre" o llevar a cabo el ritual para confirmar a la nueva partera (Paul y Paul, 1975: 711). El altar de la cruz en la montaña no sólo simboliza la fertilidad y la renovación, sino que también, por estar colocado fuera del pueblo, se vincula con la naturaleza, lo salvaje, lo peligroso, contrapuesto al espacio de la comunidad, donde residen el orden, la ley, lo socializado; igualmente que se oponen los tiempos en que se celebran los ritos: la noche y el día; o bien el mundo indígena y el cristiano, los espíritus guardianes y los santos, a quienes se les pide la protección de la partera recién iniciada. Mundos que algún día fueron opuestos, y que en la actualidad son hábilmente integrados dentro de las creencias actuales para alcanzar la protección tanto de la religión católica, como de los antiguos poderes indígenas.

La partera como "especialista de lo sagrado", participa de la sacralidad con mayor plenitud que el resto de la comunidad; es una elegida de los seres sobrenaturales, ha recibido una iniciación específica, participa del poder y de la esencia de las divinidades (García y Petrich, 1983: 48). ${ }^{11}$

Otro símbolo entre los mochós, que se le otorga a la partera o yoq'loman, y que la identifica con el chamán o qaman, es que ambos tienen como signo de su poder, de su iniciación ritual, un altar con "su cruz" de ocote, y celebran el 3 de mayo la fiesta de la Santa Cruz. Cada siete años, la que funge como madrina de la cruz de la partera y las personas que se sienten agradecidas con ella, adornan el altar con papeles cortados y guirnaldas y construyen un arco de madera que llevan a bendecir a la iglesia antes de instalarlo frente al altar de la mujer, quien a su vez agradecerá con comida a parientes, amigos y pacientes (Petrich, 1985: 42-43, 123).

"Su cruz" debe simbolizar un axis mundi que comunica a los tres niveles del cosmos; por la intersección de las dos rectas, es un medio de comunicación con el mundo de lo divino, donde se entremezclan el

11 "?ahawail: esta forma de ?ahawal, término genérico para designar a las divinidades - propietarias - señores y a quien se añade $i l$ : abstractivo, por lo que hace referencia al poder de esas divinidades". 
tiempo y el espacio; es el cordón umbilical jamás cortado del cosmos, ligado al centro original. La cruz es la gran vía de comunicación que la partera precisa, porque el niño que nace proviene de "allá", y la partera que lo recibe acompaña el alma del recién nacido desde el ámbito de lo sagrado al mundo profano, por lo que en cierta medida es un "psicopompo"; pero, en sentido opuesto al de otros curanderos, que más bien acompañan a las almas en su viaje de lo profano a lo sagrado. Quizá por ello se coloque el arco que se lleva a bendecir sobre la cruz, pues simboliza un umbral sagrado, una entrada al mundo sobrenatural.

"Su cruz" es también un árbol sagrado de la vida; por ello éste se adorna con guirnaldas y papeles multicolores cada siete años, cuando su fertilidad decae y necesita renovarse; es el cosmos vivo en perpetua regeneración. La partera trae a la vida, la renueva; de ahí que entre sus símbolos de poder estén la cruz y el arco.

La validación sobrenatural, con todos los símbolos asociados, le otorga poder a la partera para efectuar los rituales propios del parto, para interpretar los diversos designios del nacimiento, esto es las características futuras del niño; la partera debe anunciar, por ejemplo, si el nuevo ser es un hombre elegido; debe tener la facultad para conocer el número y sexo de los futuros hijos de la pareja. Los conocimientos que ella posee son considerados peligrosos y sólo si ha sido iniciada puede ejercer su profesión sin riesgo. Más aún, porque durante el parto la madre desprende una gran cantidad de "calor" y sangre impura; por ello la comadrona debe estar ritualmente preparada.

Coexistiendo con estas parteras iniciadas, y en muchos casos superando en número, en gran parte de las comunidades mayenses las comadronas son ancianas experimentadas, o bien mujeres instruidas en obstetricia; por ende, no se considera que éstas tengan poderes sobrenaturales. Los tzeltales de Cancuc indican que no existen las parteras profesionales, sino que todas las viejecitas "saben pepenar criatura" (Guiteras, 1992: 171); ${ }^{12}$ entre los tzotziles se agrega que se prefiere que la partera sea una pariente cercana, la madre, la suegra o la hermana (Guiteras, Los peligros...: 100); ${ }^{13}$ igual sucede en las comunidades yucatecas (Redfield y Villa Rojas, Chan Kom...: 72; Maas, Transmisión...: 3). ${ }^{14}$ Otros grupos, como los chortís, mencionan que

${ }^{12}$ Las notas de campo fueron tomadas por la autora en 1944.

${ }^{13} \mathrm{La}$ autora realizó su investigación entre los tzotziles a mediados de este siglo.

${ }^{14}$ Redfield y Villa Rojas, pioneros del trabajo de campo entre las comunidades mayas yucatecas, trabajaron entre 1930 y 1940; en tanto que Maas, antropóloga hablante de maya yucateco, laboró en el poblado de Chę̧ax entre 1976 y 1978. 
sólo curan con sus manos; su instrucción se reduce a la transmisión hereditaria del oficio (Wisdom, 1961: 343). ${ }^{15}$

Según los datos obtenidos en las diversas etnografías, el papel que las parteras como profesionales especializadas, con una sanción ritual, mantuvieron durante varios siglos se ha modificado en las últimas décadas. En México, además de los mochós se reportan otros casos, como por ejemplo entre los los choles de Tumbalá, Chiapas, donde las curanderas, que también funcionan como parteras, reciben en sueños el mandato divino para su profesión (Alejos, 1993). En ciertas comunidades de Guatemala, aunque también su carácter tradicional está en camino de desaparecer, "la costumbre" se conserva más. La medicina occidental intenta desplazarlas y las considera como supersticiosas, ignorantes y aun peligrosas, por lo que algunas mujeres emplean determinadas técnicas y medicinas modernas para tratar de conservar su prestigio, logrando por esta vía resolver ciertas dificultades en los partos.

Al perder validez ritual y profesionalismo, también pierden prestigio dentro de la comunidad; por ello, en ciertos pueblos, las comadronas son aquellas mujeres que necesitan dinero, por ejemplo las viudas o abandonadas; ésta es otra causa para dedicarse a esta labor: una decisión personal propiciada por factores económicos.

Como resultado de los programas de adiestramiento propiciados por los gobiernos, en la actualidad las comadronas que ejercen el oficio son más jóvenes que antaño; son mujeres de aproximadamente 35 años, que si bien tienen más vigor, no gozan del mismo prestigio ni son tan respetadas por la comunidad como las de mayor edad, y más aún si en esa comunidad existía la tradición de la sanción ritual para la partera.

También ocurre que algunas parteras tradicionales aprenden prácticas asépticas y técnicas médicas brindadas por la obstetricia occidental, y con ello aumentan su reputación.

Los cursos de salud pública modifican aceleradamente la forma de reclutar a la partera y también su labor, ya que se le prohíbe emplear hierbas en los baños dentro del temascal; se le aconseja también que se le brinde a la embarazada toda clase de alimentos, y aún se le recomienda que la parturienta asuma una posición horizontal durante el alumbramiento (Cosminsky, 1977: 309) (la posición tradicional, más fisiológica, es en cuclillas, sentada en una pequeña silla, o arrodillada y con las palmas de la mano en el piso).

${ }^{15}$ El trabajo de campo de Wisdom también es bastante antiguo, de alrededor de los treintas. 
Las parteras que reciben sanción sobrenatural, es decir que poseen su "don-destino", son más respetadas por su grupo social; a esto se aúna su edad, experiencia, conocimientos obstétricos y rituales, tanto como su reputación. Por ello, su comunidad les muestra ciertas deferencias, como un título reverencial, besarles la mano, la petición formal de sus servicios, que incluye regalos de comida y bebida.

Para requerir su trabajo y experiencia, se acercan a ella con un cierto ceremonial, ya sea en el tercero, el quinto o bien el séptimo mes. $\mathrm{La}$ petición formal le corresponde a cualquiera de los suegros o al futuro padre, dado que por respeto los futuros padres evitan tratar con la madre de la joven asuntos de sexo o de embarazo.

Entre los quichés, al iniciarse el diálogo entre la partera y la familia, se recalca que aquella continúa las costumbres de nuestra Señora María Santana Porpet (Bunzel, Chichicastenango: 136). En términos generales, la respuesta inicial es negarse a aceptar el trabajo por falta de tiempo; más tarde accede y se acuerdan el pago y las atenciones que se le tendrán durante su estancia en la casa de la "enferma"; se aclara a cargo de quién estarán sus alimentos, pues de acuerdo con la costumbre, si la partera vive lejos del lugar de su trabajo, puede permanecer varios días en la casa de la nueva madre.

La familia, como un signo de reconocimiento del papel de la comadrona, le lleva algunos regalos, como pan, chocolate y aguardiente de caña o ron; al aceptar los presentes, acepta el trabajo. A través de estas dádivas se establece un lazo de unión que implica una mutua responsabilidad entre el oferente y el beneficiario. También le entregan velas e incienso para santa Ana y para otros santos y espíritus, para que ellos favorezcan a la madre, porque la comadrona funge como un intermediario entre el mundo de los hombres y el de las energías sobrenaturales. Una vez aceptado el cargo, la partera visita a la joven a fin de confirmar el diagnóstico (Reina, 1973: 325; Cosminsky, 1976: 108). ${ }^{16}$

En algunos grupos, como los lacandones o los chontales, donde no existe la partera profesional, la mujer que asiste a la madre, ya sea la suegra, algún pariente femenino o una vecina, acude sin más preámbulos al iniciarse los dolores del parto.

La partera inicia su labor desde que acepta el cargo, visita a su paciente y le da ayuda psicológica a la embarazada, quien sobre todo teme fallecer en el parto; le ofrece tranquilidad y seguridad, apoyo social y emocional y reduce sus angustias.

${ }^{16}$ Rubén Reina trabajó en Chinautla, con hablantes del pokomam entre 1953 y 1962. 
Asimismo, aconseja a la futura madre sobre los cuidados que debe tener durante su preñez, qué alimentos puede ingerir, qué conductas debe evitar, interpreta sus sueños, le indica algunas ceremonias sencillas para su defensa, implora la protección de santa Ana y predice el sexo del infante. Cuando llega el momento, la acompaña durante la labor de parto, y en caso de que éste se prolongue, le ofrece bebidas para acelerarlo.

La partera recibe diversos nombres según la comunidad de que se trate; todos ellos hacen referencia a alguna de sus funciones: los mochós la llaman yoq'loman, 'aquella, la que da masajes'; los kekchi', aj xocol c'ulal, 'la que levanta, la que recoge al niño' (Haeserjin, 1979); o bien entre los tzotziles y los tzeltales tam'olol 'recogedora, partera', 'la que levanta al niño en el momento del nacimiento' (Laughlin y Haviland, 1988: 300, 308). ${ }^{17}$

Una forma común en varias etnias es llamarlas con la palabra correspondiente a la de 'abuela', pues al igual que una madre, la partera cuida y protege a la parturienta; durante la preñez y el trabajo de parto se crea un vínculo indisoluble entre la partera y la madre; aquélla se convierte en 'abuela', en protectora del pequeño. También el concepto podría aludir a que lo anciano reviste un cierto carácter sagrado, porque el solo hecho de haber envejecido evoca una suerte de vínculo con las fuerzas supratemporales de conservación; resistir el paso del tiempo es como una prueba de solidez, de autenticidad, de verdad; el anciano alcanza conocimientos, experiencia. ${ }^{18}$ En cakchiquel se le conoce como qexelom, que además de 'partera', significa 'madrina', es decir, una madre ritual; la especialista establece un vínculo ritual con el pequeño que recibe. La partera, al ayudar a la madre a dar a luz, funciona como "otra madre" para el recién nacido, porque ella también lo ha traído a la vida.

Del análisis de los rituales de iniciación de la partera se infiere la relevancia que su figura ha tenido a lo largo de la historia; ella es una mujer consagrada y por ende puede ejercer su oficio. La persona se

${ }^{17}$ En tzotzil se incluyen las siguientes entradas: tamolah, htamol, ytam'unen, con el mismo significado. Ara (1986: 335 y 376 ) registra para los tzeltales: mol-alal, y tam alalgh.

${ }^{18}$ Los grupos que se refieren a ella como abuela son los zutuhiles, que la llaman iyom (Paul y Paul, 1975: 707); entre los tojolabales, me'xep (Ruz, 1982: 131); los choles, $c o$ '-l o mam, cuyos significados son: 'hermano de la abuela paterna', 'partera que atiende un nacimiento' (Aulie y Aulie, 1978). Los quichés la llaman tichú, palabra compuesta de atia y chuch, y lo traducen como 'abuela ritual' (Schultze, 1947 o 1954: 111). 
transforma por la eficacia simbólica de los ritos, y esta eficacia simbólica actúa sobre lo real, es decir, su investidura ejerce una transformación real en la mujer, en primer lugar porque transforma la imagen que los otros miembros de la comunidad tienen de la partera (de ahí los comportamientos que adoptan con ella, como los títulos de respetabilidad conferidos); al mismo tiempo transforma la representación que la partera tiene sí misma, y los comportamientos a los que se cree obligada a adoptar para ajustarse a su papel; desde el momento en que se le confiere su iniciación, tiene que vivir de acuerdo con su nueva naturaleza social.

A la par de estas conductas que requiere la mujer para consagrarse (en muchos casos ideales), se observa con cierta nostalgia y preocupación cómo hoy día se pierden sus funciones sobrenaturales, un síntoma más de los cambios sufridos por los grupos mayas contemporáneos.

\section{Bibliografía}

Alejos, José

1993 "Notas de trabajo de campo, Tumbalá, Chiapas, temporada 1993", mecanoescrito.

ARA, fray Domingo de

1986 Vocabulario en lengua tzeldal según el orden de Copanabastla, editor Mario Humberto Ruz, UNAM, IIF, CEM, México. (Serie de Fuentes para el Estudio de la Cultura Maya, 4.)

Aulie H., Wilbur, y Evelyn W. Aulie

1978 Diccionario ch'ol-español, español ch'ol, Instituto Lingüístico de Verano, México. (Serie de Vocabularios y Diccionarios Indígenas, núm. 21.)

Chevalier, Jean, y Alain GheERBrant

1988 Diccionario de los símbolos, Herder, Barcelona.

CosminsKy, Sheila

1976 "Birth Rituals and Symbolism: a Quiché Maya-Black Carib Comparison", en Ritual and Symbol in Native Central America, editado por Philip Young y James Howe, Oregon. (University of Oregon Anthropological Papers, núm. 9.)

1977 "El papel de la comadrona en Mesoamérica", en América Indígena, órgano trimestral del Instituto Indigenista Interamericano, vol. XXXVII, núm. 2, México, abril-junio, pp. 305-336.

1981 Chichicastenango, Editorial "José de Pineda Ibarra", Ministerio de Educación, Guatemala. 
Eliade, Mircea

1975 Iniciaciones místicas, Editorial Taurus, Madrid. (Ensayistas, núm. 134.)

1982 El chamanismo y las técnicas arcaicas del éxtasis, Fondo de Cultura Económica, México. (Sección de obras de Antropología.)

García-Ruiz, Jesús, y Perla Petrich

1983 "La femme, la lune, la fécondation chez les Mocho", resumen de Objets et mondes, la Reveu du Musée de l'Homme, 23, fasc. 1-2, París, Printemps-Ete.

Garduño OrTega, Ana

s.f. "Los bultos sagrados mesoamericanos. Un acercamiento", mecanuscrito.

Garza C., Mercedes de la

1990 Sueño y alucinación en el mundo náhuatl y maya, UNAM, IIF, CEM, México.

GENNEP, Arnold van

1986 Los ritos de paso. Estudio sistemático de las ceremonias de la puerta y del umbral..., versión castellana de Juan Aranzadi, Taurus Ediciones, Madrid.

1992 Cancuc. Etnografía de un pueblo tzeltal de los Altos de Chiapas 1944, edición preparada por V. M. Esponda y Efigenia Ma. Chapoy Liceaga, 1984, Gobierno del Estado de Chiapas, Consejo Estatal de Fomento en la Investigación y Difusión de la Cultura, DIF, Chiapas, Instituto Chiapaneco de Cultura, México.

HAESERIJN V., Esteban

1979 Diccionario K' ekchi'-Español, Editorial "Piedra Santa", Guatemala.

LANDA, fray Diego de

1966 Relación de las cosas de Yucatán, 9a. ed., Editorial Porrúa, México. (Biblioteca Porrúa, 13.)

Laughlin, Robert M., y John Haviland

1988 The Great Tzotzil Dictionary of Santo Domingo Zinacantan: with Gramatical Analisis and Historical Commentary, 3 vols., Smithsonian Institution, Washington, D.C. (Smithsonian Contribution to Anthropology, 31.)

PAUL, Lois, y Benjamin PaUL

1975 "The Maya Midwife as Sacred Specialist: a Guatemalan Case", en American Ethnologist, vol. 2, núm. 4, pp. 707-726.

Petrich, Perla

1985 La alimentación mochó: Acto y palabra. (Estudio etnolin- 
güístico), Universidad Autónoma de Chiapas, Centro de Estudios Indígenas. (Serie Monografías, 1.)

REINA, Rubén

1973 La ley de los santos. Un pueblo pokomam y su cultura de comunidad, Editorial "José Pineda Ibarra", Ministerio de Educación, Guatemala.

Ruz, Mario Humberto

1982 Los legítimos hombres. Aproximación antropológica al grupo tojolabal, vol. II, UNAM, IIF, CEM, México.

SCHULTZE JENA, Leonhard

1954 La vida y las creencias de los indígenas quichés de Guatemala, traducción de Antonio Goubaud Carrera y Herbert D. Sapper, Ministerio de Educación Pública, Guatemala. (Biblioteca de Cultura Popular, 49.)

Wispom, Charles

1961 Los chortís de Guatemala, Editorial del Ministerio de Educación Pública "José de Pineda Ibarra", Guatemala. (Seminario de Integración Social Guatemalteca, publicación núm. 10.) 